\title{
Industry 4.0 - Relationship Between Capital Equipment and Labor Productivity
}

\author{
Peter MARINIČ* and Pavel PECINA \\ Masaryk university, Brno, Czech Republic; marinic@ped.muni.cz; ppecina@ped.muni.cz \\ * Corresponding author: marinic@ped.muni.cz
}

\begin{abstract}
Using new technology in production process is naturally connected with the economic development due to attempt to increase labor productivity and/or decrease in unit production costs. In last decades, term Industry 4.0 is used for such cases, as industrial revolution connected with new technology, especially information and communication technology, used in production process. Industry 4.0 is also connected with a fear of disappearing different kind of occupations replaced by new technology and with the fear of lack of employees in other occupations requiring suitable but not yet existing qualification. In the article we present the development of economic indicators and ratios based on production output, compensation on employees, capital equipment, volume of workers, and hours worked to illustrate development of labor productivity in 1995-2018 in Czech Republic, Slovakia, Poland, Hungary, Austria, and Germany. We present results about significant changes in economic structure in analyzed countries, but as results of economic development or economic transformation process. Thus, we try to articulate that the development is rather economic evolution than industrial revolution and that there is no reason to be afraid of Industry 4.0 process.
\end{abstract}

Keywords: economic development; economic indicators; labor productivity; capital equipment; Industry 4.0

\section{JEL Classification: O11; E24}

\section{Introduction}

In the last years, the debate about the Industry 4.0 has increased and a lot of people are interested in this topic. It is no longer the topic of only the technicians and economists, but also the politicians of local and national level are debating it, and the teacher as well (Mason \& Vanark, 1994; Pecina \& Sládek, 2017). All the above-mentioned groups are trying to implement this topic to their agenda and to prepare for the inevitable changes which the Industry 4.0 is about to bring to our lives. The debate is not only about the direct changes in the industrial flow, process of making things and the economic influence on the entrepreneurs, but also about the influence on the labor market, national policy and the education system as well. The politicians are debating the steps needed to prepare for the changes in the labor market structure in the sense of the appropriate skills of the workers, and with the connection with the teachers they try to find out what new skill, competencies in the fashion style of speech, are needed to develop in the pupils and students as future workers (Brahama, Tripathi, \& Sahay, 2020) There are a lot of emotion in those debates due to fear of losing the competitive 
position of the national economy, losing the high educated and skilled workers, and other factors. Especially the fear of radical changes in the economic structure of the industrial sectors connected with the Industry 4.0 initiatives.

But if we look for the examples in the human history (Settsu \& Takashima, 2020; Hasino \& Otsuka, 2020), there are a lot of cases where there was similar fear of exchanging the human force as workers by the force of inventions and especially machines. Nowadays we are not even able to imagine our life without the mobile phones and other mobile devices making the communication easy and very available. We are not able to imagine constructing a lot of building and structures without help of different kind of tools and machinery. And it is true that it creates a lot of pressure to our ability to use those devices and technology. But we as the humankind are very adaptable and creative. The emotional point of view connected with the fear of losing the individual competitive position of each of us as the worker not depending on the type of work, we are doing is understandable at the individual level. But there should by some-kind of global perspective which could make as calm and provide us with the suitable understanding that all the changes of implementation of Industry 4.0 to life would have positive effect on our lives.

\section{Methodology}

The main idea of the article is to point out the development of chosen economical indexes to show the development of industrialization process in the chosen European countries, namely Czech Republic (CZ), Germany (DE), Hungary (HU), Austria (AT), Poland (PL), and Slovakia (SK). The indexes were chosen in such way that they can illustrate the labor productivity (Szirmal, 2019; Vonyo \& Klien, 2019) and other connected economic indexes (Gashenko et al., 2020; Xu, Xu \& Li, 2018).

Labor productivity, signed as workers productivity, is computed as ratios of output $(\mathrm{O})$ to number of employees within total employment as volume of persons (PTE). Due to inventions, automatization and technological development connected with the overall economic development it is assumed that labor productivity will increase in time. However, due to Industry 4.0 as the revolutionary process, the abrupt increase should be identified. This abrupt increase should also occur due to replacement of manual work by machinery, in other words by increasing personal capital equipment as ratio of consumption of fixed capital (CoFC) to number of employees within total employment as volume of persons (PTE).

The workers wage as ratio of compensation of employees $(\mathrm{CoE})$ to number of employees within total employment as volume of persons (PTE) and the hour worked per employee as ratio of hours worked by employees within total employment (HTE) to number of employees within total employment as volume of persons (PTE) is also analyzed. As manifestation of the initiative, there should be reduction in the volume of work per employee, and as result of increased labor productivity wages could increase. Both are positive consequences of Industry 4.0 process and something that employees should not be afraid of.

The analysis also includes two ratios, first as personal costs (compensation of employees) to output and second as fixed cost (consumption of fixed costs) to output used for analysis of the economic impacts connected with the changes in range of labor and capital equipment. 
The negative relationship is assumed because of more intensive increase in capital equipment per employee than labor costs.

For the analysis, the data from Eurostat database were used. The data were analyzed in the time-period from 1995 till 2018, which is the longest range available. In the fact that there were, and in some countries still are, different currencies, the Euro was chosen as the summarizing currency for the whole time-period.

The selected data were (with abbreviation in brackets):

- (O) output,

- (CoE) compensation of employees,

- (CoFC) consumption of fixed capital,

- (GFCF) gross fixed capital formation (total fixed assets),

- (HTE) hours worked by employees within total employment,

- (PTE) number of employees within total employment as volume of persons.

Those data were analyzed for the six chosen economies using breakdown to sector type according to NACE classification as follows (with abbreviation in brackets):

- (All) total - all NACE activities,

- (A) agriculture, forestry, and fishing,

- (B-E) industry except construction,

- (F) construction,

- (G-I) wholesale and retail trade, transport, accommodation, and food service,

- (J) information and communication,

- (K) financial and insurance activities,

- (L) real estate activities,

- $\quad(\mathrm{M}-\mathrm{N})$ professional, scientific, and technical activities; administrative and support service activities,

- (O-Q) public administration, defense, education, human health, and social work activities,

- (R-U) Arts, entertainment and recreation, other service activities; activities of household and extra-territorial organizations and bodies.

From the abovementioned ratios the most important for the influence of the Industry 4.0 are the following (computation of ratios from economic variables in brackets):

- workers productivity $(\mathrm{O} / \mathrm{PTE})$,

- $\quad$ workers wage (CoE/PTE),

- personal capital equipment (CoFC/PTE),

- ratio of personal costs $(\mathrm{CoE} / \mathrm{O})$,

- ratio of fixed costs $(\mathrm{CoFC} / \mathrm{O})$,

- $\quad$ hours worked per employee (HTE/PTE).

In the analysis there were selected economic variables (output, compensation of employees, consumption of fixed capital, gross fixed capital formation, hours worked by employees within total employment, number of employees within total employment as 
volume of persons) used for computing the different types of ratios (workers productivity, workers wage, personal capital equipment, ratio of fixed costs, ratio of personal costs, hours worked per employee). These variables were analyzed through the year-to-year per cent change in the selected time-period form 1995 till 2018 for each country separately - results are presented in the tables. In the graph there are mutual comparison of the selected ratios in the first year, 1995, and the last year, 2018, of the analyzed period and changes during the period presented to illustrate the development of chosen ratios in all countries. To identified relationship between chosen ratios in more sensitive way the sector breakdown according to NACE was used, so more variables were obtained and there was higher possibility to identify specific sectors, with interesting results for further analysis.

If Industry 4.0 is truly revolutionary process, abrupt change in data should occur, but if it is a natural development, evolutionary process, then the change should be smooth.

\section{Results}

In Figure 1, there is presentation of the indicators of chosen EU countries which were used for computation of the following ratios below. It consists the volume of indicators in 2018 , the last year of the analyzed period which could be considered the best approximation of the current state, the absolute volume of difference between the first and the last year (1995 to 2018 difference), and the ratio in per cent of the year-to-year change of each indicator.

\begin{tabular}{|c|c|c|c|c|c|c|c|}
\hline \multicolumn{4}{|c|}{ Output* } & \multicolumn{4}{|c|}{ Gros Fixed Capital Formation (Total Fixed Assets)* } \\
\hline Country & 2018 & 1995-2018 & 1995-2018 ( $r-r ; \%)$ & Country & 2018 & 1995-2018 & $1995-2018(r-r ; \%)$ \\
\hline $\mathrm{CZ}$ & 478,379 & 378,338 & 7.04 & $\mathrm{CZ}$ & 55,485 & 39,938 & 5.69 \\
\hline DE & $6,189,483$ & $2,851,322$ & 2.72 & DE & 707,719 & 242,210 & 1.84 \\
\hline $\mathrm{HU}$ & 258,487 & 190,454 & 5.98 & HU & 33,677 & 25,953 & 6.61 \\
\hline AT & 715,461 & 412,596 & 3.81 & AT & 92,365 & 45,726 & 3.02 \\
\hline PL & $1,000,777$ & 797,700 & 7.18 & $\mathrm{PL}$ & 90,684 & 71,729 & 7.04 \\
\hline SK & 210,723 & 176,773 & 8.26 & SK & 18,765 & 14,769 & 6.96 \\
\hline \multicolumn{4}{|c|}{ Compensation of Employees ${ }^{\star}$} & \multicolumn{4}{|c|}{ Consumption of Fixed Capital ${ }^{*}$} \\
\hline Country & 2018 & 1995-2018 & 1995-2018 (r-r;\%) & Country & 2018 & 1995-2018 & $1995-2018(r-r ; \%)$ \\
\hline $\mathrm{CZ}$ & 93,546 & 75,386 & 7.39 & $\mathrm{CZ}$ & 41,864 & 32,307 & 6.63 \\
\hline DE & $1,770,255$ & 714,566 & 2.27 & $\mathrm{DE}$ & 608,731 & 285,894 & 2.80 \\
\hline HU & 57,326 & 41,356 & 5.71 & HU & 21,257 & 14,488 & 5.10 \\
\hline AT & 185,109 & 91,108 & 2.99 & AT & 69,261 & 40,038 & 3.82 \\
\hline $\mathrm{PL}$ & 195,213 & 151,821 & 6.76 & $\mathrm{PL}$ & 56,809 & 41,067 & 5.74 \\
\hline SK & 37,377 & 31,366 & 8.27 & SK & 15,141 & 10,594 & 5.37 \\
\hline \multicolumn{4}{|c|}{ Thousand Hours Worked } & \multicolumn{4}{|c|}{ Thousand Persons } \\
\hline Country & 2018 & 1995-2018 & 1995-2018 (r-r;\%) & Country & 2018 & 1995-2018 & $1995-2018(r-r ; \%)$ \\
\hline $\mathrm{CZ}$ & $9,666,520$ & 314,832 & 0.14 & $\mathrm{CZ}$ & 5,417 & 312 & 0.26 \\
\hline DE & $62,344,000$ & $4,118,000$ & 0.30 & DE & 44,854 & 6,812 & 0.72 \\
\hline $\mathrm{HU}$ & $8,067,981$ & 387,188 & 0.21 & HU & 4,666 & 724 & 0.74 \\
\hline AT & $7,239,410$ & 874,276 & 0.56 & AT & 4,489 & 902 & 0.98 \\
\hline PL & $32,842,692$ & $2,057,962$ & 0.28 & PL & 16,404 & 1,617 & 0.45 \\
\hline SK & $4,123,329$ & 218,604 & 0.24 & SK & 2,420 & 313 & 0.60 \\
\hline
\end{tabular}

Figure 1. Analyzed economic indicators of chosen EU countries (Eurostat database, 2020) 


\begin{tabular}{|c|c|c|c|c|c|c|c|}
\hline \multicolumn{4}{|c|}{ Productivity per em ployee* } & \multicolumn{4}{|c|}{ Wage per employee* } \\
\hline Country & 2018 & 1995-2018 & $1995-2018(r-r ; \%)$ & Country & 2018 & 1995-2018 & $1995-2018(r-r ; \%)$ \\
\hline $\mathrm{CZ}$ & 88,309 & 68,714 & 6.77 & $\mathrm{CZ}$ & 17,269 & 13,712 & 7.11 \\
\hline DE & 137,992 & 50,242 & 1.99 & $\mathrm{DE}$ & 39,467 & 11,716 & 1.54 \\
\hline HU & 55,391 & 38,136 & 5.20 & $\mathrm{HU}$ & 12,284 & 8,234 & 4.94 \\
\hline AT & 159,380 & 74,949 & 2.80 & AT & 41,236 & 15,031 & 1.99 \\
\hline $\mathrm{PL}$ & 61,009 & 47,276 & 6.70 & $\mathrm{PL}$ & 11,901 & 8,966 & 6.28 \\
\hline SK & 87,079 & 70,968 & 7.61 & SK & 15,446 & 12,593 & 7.62 \\
\hline \multicolumn{4}{|c|}{ Productivity per hour* } & \multicolumn{4}{|c|}{ Wage per hour* } \\
\hline Country & 2018 & $1995-2018$ & 1995-2018 (r-r;\%) & Country & 2018 & 1995-2018 & 1995-2018 (r-r;\%) \\
\hline $\mathrm{CZ}$ & 49.49 & 38.79 & 6.89 & $\mathrm{CZ}$ & 9.68 & 7.74 & 7.23 \\
\hline DE & 99.28 & 41.95 & 2.42 & DE & 28.39 & 10.26 & 1.97 \\
\hline HU & 32.04 & 23.18 & 5.75 & $\mathrm{HU}$ & 7.11 & 5.03 & 5.49 \\
\hline AT & 98.83 & 51.25 & 3.23 & AT & 25.57 & 10.80 & 2.42 \\
\hline $\mathrm{PL}$ & 30.48 & 23.88 & 6.88 & $\mathrm{PL}$ & 5.94 & 4.53 & 6.46 \\
\hline SK & 51.11 & 42.41 & 8.01 & SK & 9.06 & 7.53 & 8.01 \\
\hline \multicolumn{4}{|c|}{ Hours worked per employee } & \multicolumn{4}{|c|}{ Capital equipment per em ployee* } \\
\hline Country & 2018 & 1995-2018 & 1995-2018 (r-r;\%) & Country & 2018 & 1995-2018 & $1995-2018(r-r ; \%)$ \\
\hline $\mathrm{CZ}$ & 1,784 & -47 & -0.11 & $\mathrm{CZ}$ & 10,243 & 7,197 & 5.42 \\
\hline $\mathrm{DE}$ & 1,390 & -141 & -0.42 & $\mathrm{DE}$ & 15,778 & 3,542 & 1.11 \\
\hline HU & 1,729 & -219 & -0.52 & $\mathrm{HU}$ & 7,217 & 5,258 & 5.83 \\
\hline AT & 1,613 & -162 & -0.41 & AT & 20,576 & 7,574 & 2.02 \\
\hline $\mathrm{PL}$ & 2,002 & -80 & -0.17 & $P L$ & 5,528 & 4,246 & 6.56 \\
\hline SK & 1,704 & -149 & -0.36 & SK & 7,754 & 5,858 & 6.32 \\
\hline
\end{tabular}

Figure 2. Analyzed economic ratios of chosen EU countries (Eurostat database, 2020)

In Figure 2, there are data about the state and development of the economic ratios computed according to chosen indicators. In both tables (Tab. 1 and Tab. 2) there are evident differences between the countries of Visegrad group and the Germany and Austria in both, the absolute volumes and the per cent ration of year-to-year change. Data also indicate that convergence process occurs. In all analyzed countries all analyzed indicator and almost all ratios grow. Only the number of hours worked per employee indicates slight decrease. In other words, productivity, capital equipment and wages of employees, per hour and per person, increase which lead to less hours worked per each employee. Due to constant increasing of work efficiency employees spend less time in a work and produce more output at the same time.

This identified relationships represent the motivation for further investigation. Thus, there are analysis of the relationship between the labor productivity and the capital equipment per worker (Figure 3), analysis of the relationship between the wage per employees and labor productivity (Figure 4) and analysis of the personal costs and fixed costs (Figure 5), to illustrate in more detail the mutual relationship. There seems to be a direct link from capital equipment growth through increase labor productivity to wage growth, but not significant relationship between ratios of personal costs and fixed costs growth.

As can be seen in the figures, the ratios are used for the identification of the relationship in the first year of analyzed period, 1995, and the last year, 2018, as well as for the year-toyear change of ratios. For the better, more strength, and detailed view on the relationship, and to be able to indicate possible significant influence of each economic sector, the sector breakdown according to NACE where used. However, there are some differences between 
the sectors, there are also differences between the countries, but not indicated clear clarifying information about the specific situation in some sector. Rather, it seems there is tendencies for the whole economy.

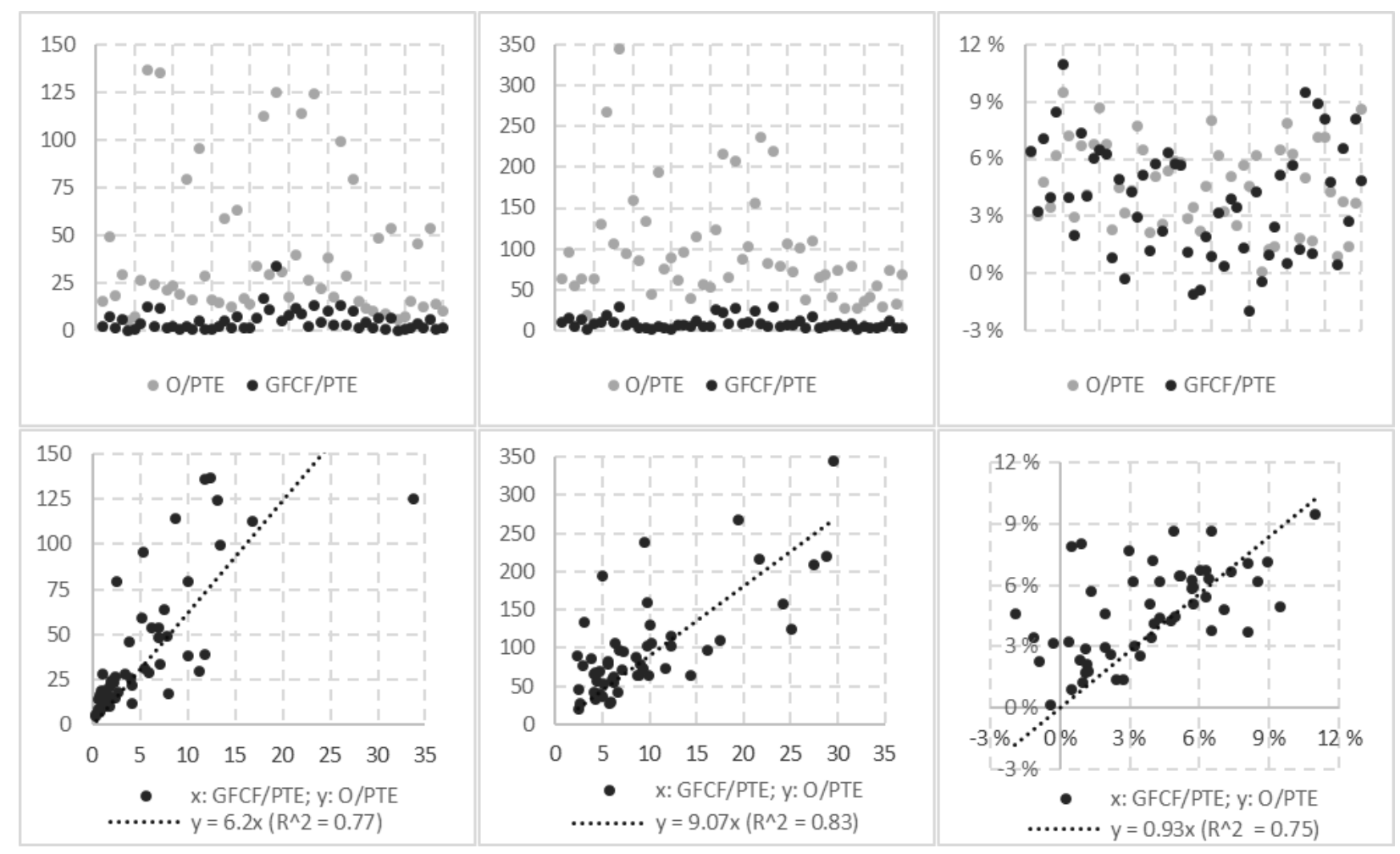

Figure 3. Relationship between productivity and capital equipment (Eurostat database, 2020)

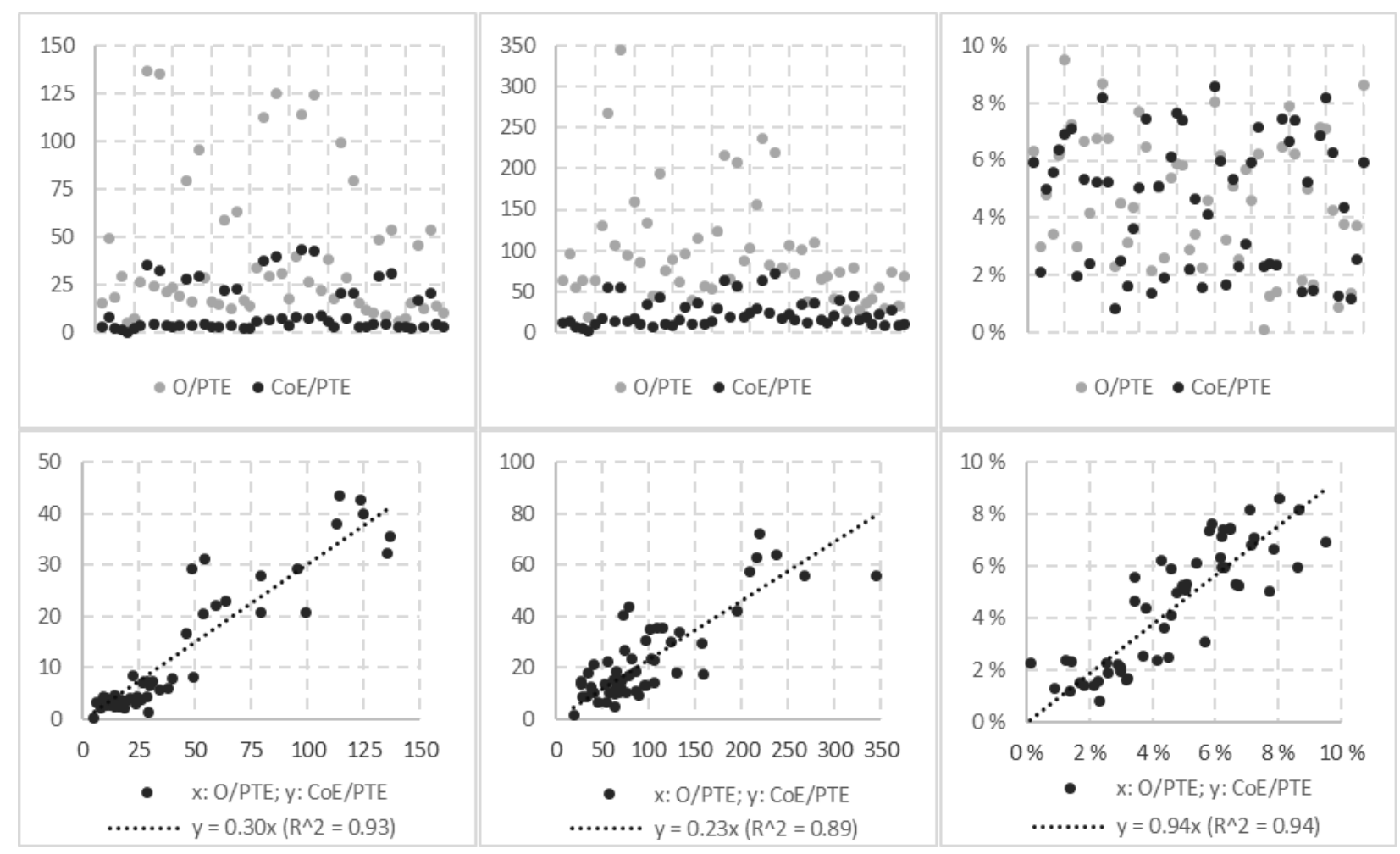

Figure 4. Relationship between wage and productivity (Eurostat database, 2020) 


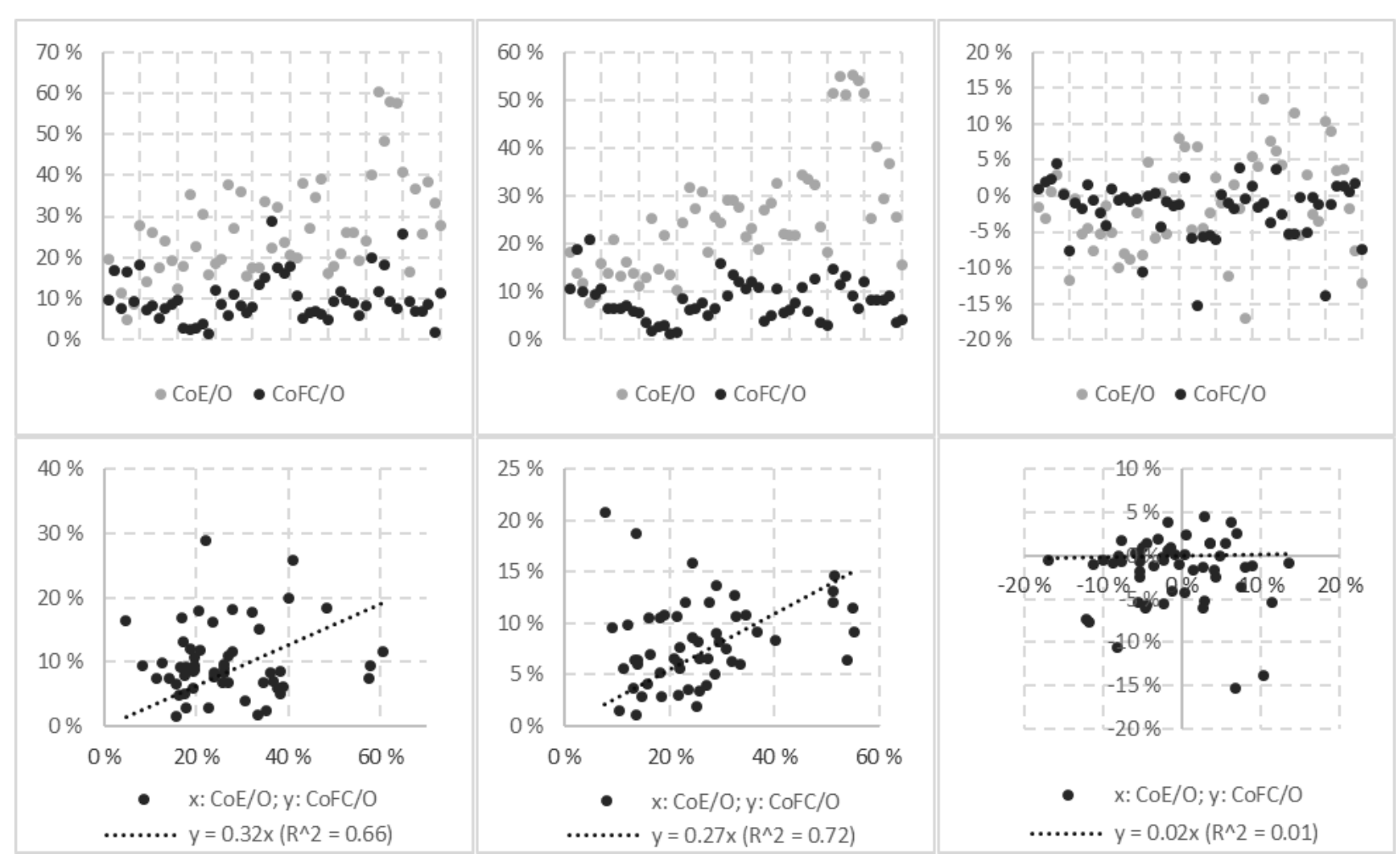

Figure 5. Relationship between personal cost and fixed costs (Eurostat database, 2020)

\section{Discussion}

Analyzed mutual relationships between analyzed ratios were not such strong as expected according to similar analyses of the development of chosen European countries, which one of the authors was participated to (Záthurecký \& Marinič, 2019). In the previous analysis, it was assumed that the use of the sectoral breakdown will help achieve more significant results with the potential to identify significant changes in specific sector. However, the data suggest that the positive effects of Industry 4.0 are in labor productivity, wage increase, and reduction of hours worked, together with the tendency of Visegrad countries to converge to Germany and Austria, but the changes are ongoing without any significant leaps. This can be due to internal differences in each sector type when using only 10 sectors according to NACE classification. There is possibility to use wider NACE classification obtaining 64 sectors and provide the analysis in this range to find out specific sectors more influenced by Industry 4.0 initiatives. But there is still the question if there is any sector with radical changes in analyzed economic variables or ratios.

We do not deny he significant contribution of technological development, informatization and digitization, which brings or is referred to as Industry 4.0, in the field of labor productivity (Kurt, 2019; Trenovski et al., 2020). The consequent effect of the increasing volume of production output, with the current aging of the European population, creates enormous opportunity to maintain prosperity and high level of consumption in the future. Even the creation of the more ecologic economy (Rutkowska \& Sulich, 2020).

Our analysis came to similar results as the analysis of the labor productivity at Slovakia in the context of the implementation of Industry 4.0, which also concluded that Slovakia is 
showing increasing economic output, increasing GDP, as well as increasing labor productivity. The contribution of Industry 4.0 is identified in industrial production, where it has the greatest potential for increasing labor productivity, but also the creation of new jobs (Grencikova, Kordos, \& Berkovic, 2020).

The specific sectors are often use as argument in debate among politicians and specifically teachers, especially teacher of vocational education and training. They expect the radical changes in specific industries and are afraid of the future of their own expertise and the usability of the pupils and students as future workers (Pecina \& Sládek, 2017). There will be need for the new competencies, abilities, and skills of employees, especially connected with the digitalization and other technologically advanced areas, putting also pressure on educational needs (Grenčíková, Kordoš, \& Navickas, 2021). Not only technology-related skills should be developed, but also creativity, emotional intelligence, critical thinking, and interpersonal skills should be developed as well (Beke, 2020).

The economic development of the chosen countries can be recognized and the convergence process of the new European Member States to the economic level of old Member States reveals as well. But these results were assumed due to common conviction of ongoing process of mutual connection between the chosen economics and their gradual harmonization. At the same time, the data point to the fact that there was no abrupt change in the analyzed time, but the development of individual indicators took place more as a continuous process of longlasting change. And here we agree with the opinion that Industry 4.0 is rather technological and economic evolution, than revolution (Asadollahi-Yazdi et al., 2020).

\section{Conclusions}

The aim of the article was to identify changes in relatively long time-period - 24 years from 1995 to 2018. According to the analysis and results it seems that the analyzed countries are developing in their production possibilities - increase of output. Also, the increase of production possibilities is enabling the enterprises to use more financial sources for the investments, and we can identify the increase of the consumption of fixed capital, increase in labor productivity and increase in compensation on employees connected with wages. This process of increasing the various economic indexes is also connected with the decrease of time spent in the work. Whole development is rather fluent change than revolution jump.

\section{References}

Asadollahi-Yazdi, E., Couzon, P., Nguyen, N. Q., Quazene, Y., \& Yalaoui, F. (2020). Industry 4.0: Revolution or Evolution? American Journal of Operation Research, 10, 241-268. https://doi.org/10.4236/ajor.2020.106014

Beke, E. (2020). The relationship and interaction between Industry 4.0 and education. Müszaki Tudományos Közlemények, 13, 36-39. https://doi.org/10.33894/mtk-2020.13.03

Brahama, M., Tripathi, S. S., \& Sahay, A. (2020). Developing curriculum for industry 4.0: digital workplaces. Higher Education Skills and Work-based Learning.

Eurostat Database. (2020). National accounts. Statistical code: nama_10_a64; nama_10_a64_e.

Gashenko, I. V., Khakhonova, N. N., Orobinskaya, I. V., \& Zima, Y. S. (2020). Competition between human and artificial intellectual capital in production and distribution in industry 4.0. Journal of intellectual capital, 21(4), 531-547. https://doi.org/10.1108/JIC-11-2019-0275 
Grencikova, A., Kordos, M., \& Berkovic, V. (2020). Impact of Industry 4.0 on Labor Productivity in the Slovak Republic. Problems and Perspectives in Management, 18(2), 396-408. https://doi.org/10.21511/ppm.18(2).2020.32

Grenčíková, A., Kordoš, M., \& Navickas, V. (2021). The Impact of Industry 4.0 on Education Contents. Business: Theory and Practice, 22(1), 29-38. https://doi.org/10.3846/btp.2021.13166

Hashino, T., \& Otsuka, K. (2020). The Rise and Fall of Industrialization: The Case of a Silk Weaving District in Modern Japan. Australian Economic History Review, 60(1), 46-72. https://doi.org/10.1111/aehr.12182

Kurt, R. (2019). Industry 4.0 in Terms of Industrial Relations and Its Impacts on Labour Life. Procedia Computer Science, 158, 590-601. https://doi.org/10.1016/j.procs.2019.09.093

Mason, G., \& van Ark, B. (1994). Vocational Training and Productivity Performance: An Anglo-Dutch Comparison. International Journal of Manpower, 15(5), 55-69. https://doi.org/10.1108/01437729410061456

Pecina, P., \& Sládek, P. (2017). Fourth Industrial Revolution and Technical Education. In L. Gómez Chova, A. López Martínez, I. Candel Torres (Eds.), International Technology, Education and Development Conference (pp. 2089-2093). IATED Academy. https://doi.org/10.21125/inted.2017.0621

Rutkowska, M., \& Sulich, A. (2020). Green Jobs on the background of Industry 4.0. Procedia Computer Science, 176, 1231-1240. https://doi.org/10.1016/j.procs.2020.09.132

Settsu, T., \& Takashima, M. (2020). Labour Productivity Growth in the Long Run: Japan, 1600-1909. Australian Economic History Review, 60(1), 5-26. https://doi.org/10.1111/aehr.12188

Szirmai, A. (2015). Socio-economic development (2nd ed.). Cambridge: Cambridge University Press. https://doi.org/10.1017/CBO9781107054158

Trenovski, B., Trpkova-Nestorovska, M., Merdzan, G., \& Kozheski, K. (2020). Labour productivity in terms of the fourth industrial revolution. Southeast European Review of Business and Economics, 1(2), 38-51.

Vonyó, T., \& Klein, A. (2019). Why did socialist economies fail? The role of factor inputs reconsidered: why did socialist economies fail? The Economic History Review, 72(1), 317-345. https://doi.org/10.1111/ehr.12734

Xu, L. D., Xu, E. L., \& Li, L. (2018). Industry 4.0: state of the art and future trends. International Journal of Production Research, 56(8), 2941-2962. https://doi.org/10.1080/00207543.2018.1444806

Záthurecký, V., \& Marinič, P. (2019). Industry 4.0 - analysis of the economic development in the chosen European countries. In 6th SWS International Scientific Conference on Social Sciences ISCSS 2019 (pp. 599-606). https://doi.org/10.5593/SWS.ISCSS.2019.2/S05.073 